\title{
Structural Behavior of Concrete Beams Containing Recycled Coarse Aggregates under Flexure
}

\author{
In-Hwan Yang $\mathbb{D},{ }^{1}$ Jihun Park, ${ }^{1}$ Kyoung-Chul Kim, ${ }^{2}$ and Hyungbae Lee ${ }^{3}$ \\ ${ }^{1}$ Department of Civil Engineering, Kunsan National University, Kunsan, Jeonbuk 54150, Republic of Korea \\ ${ }^{2}$ Structural Engineering \& Bridges Research Division, Korea Institute of Civil Engineering and Building Technology, Goyang, \\ Gyeonggi 10223, Republic of Korea \\ ${ }^{3}$ Department of Environmental Management Business, EPS Engineering, Anyang, Gyeonggi 13930, Republic of Korea
}

Correspondence should be addressed to In-Hwan Yang; ihyang@kunsan.ac.kr

Received 30 January 2020; Revised 30 April 2020; Accepted 15 June 2020; Published 4 July 2020

Academic Editor: Robert Černý

Copyright (c) 2020 In-Hwan Yang et al. This is an open access article distributed under the Creative Commons Attribution License, which permits unrestricted use, distribution, and reproduction in any medium, provided the original work is properly cited.

\begin{abstract}
The structural behavior of concrete beams containing recycled coarse aggregates (RCAs) was investigated in this study using detailed experimental data. Twelve concrete beams were tested in the experimental program: nine beams with varying RCA contents and three control beams with natural coarse aggregates (NCAs). The parameters for investigating the structural behavior of the RCA concrete beams under flexure were the RCA content $(30 \%, 50 \%$, and $100 \%)$ and tensile rebar ratio $(0.50 \%, 0.79 \%$, and $1.14 \%)$. The crack pattern of the RCA beams was similar to that of the NCA beams; however, the RCA beams exhibited smaller crack spacing than the NCA beams. The flexural strength was slightly affected by the RCA content. However, the ductility of the beam was not significantly influenced by the RCA content. A comparison of the experimental results and the calculations from the ACI 318 and EC 2 provisions for the flexural strength showed that the current provisions conservatively predicted the flexural strength of the RCA concrete beams.
\end{abstract}

\section{Introduction}

The replacement of aging infrastructures and buildings results in large quantities of construction waste, especially concrete waste. Concrete waste generated from demolition work contains many aggregates. Because aggregates occupy the majority of the concrete volume, it is reasonable to investigate reusing the aggregates from concrete waste to create new concrete [1-3]. Recycled coarse aggregates (RCAs) have been used in many laboratory experiments [4-6].

Due to the potential economic and environmental benefits, interest in technology for processing waste concrete and the use of RCAs is rapidly increasing $[7,8]$. The advantages of using RCAs include a reduction in the use of natural coarse aggregate (NCA) resources and a decrease in the amount of waste disposed in landfills, thereby diminishing environmental pollution.

Despite the high demand, RCAs are primarily used in road bases and nonstructural concrete. Only a small percentage of RCAs is used in structural concrete because the quality of RCAs is less reliable than that of NCAs. Comprehensive experimental research has been performed to assess the properties of both NCA and RCA concrete at the material level [9-14]. Several experimental studies have investigated the flexural behavior of RCA concrete beams at the structural level [15-21]; however, the results from these studies are contradictory.

Seare-Paz et al. [15] studied the structural behavior of concrete beams containing three different RCA contents: $20 \%, 50 \%$, and $100 \%$. Their results showed that the moment capacity of the RCA beams was similar to that of conventional concrete beams. They also reported that the crack pattern in the RCA beams was similar to that in conventional concrete beams.

Sunayana and Barai [16] performed an experimental study on concrete beams with $100 \%$ recycled aggregates at three different rebar ratios. Their results showed that the moment capacity of the RCA and conventional concrete 
beams was similar at low rebar ratios. In addition, numerous closely spaced cracks were present in the RCA beams.

To investigate the flexural behavior of semiprecast T-beams, Fahmy and Idriss [17] performed bending tests on three beams containing a combination of recycled fine aggregates and RCAs and compared the results to those from the NCA concrete beam. Their test results showed that the load capacity of the RCA beams was greater than that of the control beam.

Kang et al. [18] tested RCA beams with $135 \times 270 \mathrm{~mm}^{2}$ cross sections for both normal- and high-strength concrete. The RCA beams had RCA contents up to $30 \%$ for highstrength concrete and up to $50 \%$ for normal-strength concrete. The test results showed that the RCA beams sustained more cracks and exhibited less ductility than the conventional concrete beams.

Arezoumandi et al. [19] tested eight beams, including four RCA beams. Their test results showed that the crack spacing in the RCA beams was smaller than that in the conventional concrete beams. Moreover, the RCA beams exhibited a higher ultimate deflection than the conventional concrete beams. However, the ultimate moments of the RCA beams and the conventional concrete beams were similar.

Although several studies have investigated the flexural performance of RCA concrete beams, the results are conflicting. In addition, there are few test results of large-scale RCA beams with RCA contents up to $100 \%$. Therefore, the purpose of this study was to explore the structural behavior of RCA concrete beams under flexure.

A total of twelve concrete beams were created and then tested under four-point bending. Nine beams were constructed with RCA concrete, and three control beams were constructed with NCA concrete. The parameters in this study were the RCA content $(30 \%, 50 \%$, and $100 \%)$ and tensile rebar ratio $(0.50 \%, 0.79 \%$, and $1.14 \%)$. The investigation of structural behavior included the cracking pattern, ductility, and ultimate flexural strength.

\section{Research Significance}

Extensive experimental studies of flexural characteristics are scarce for RCA beams, especially for concrete beams with RCA contents above $50 \%$. The use of RCAs is increasing as worldwide environmental problems require more ecofriendly solutions. Therefore, in this study, the characteristics of the structural behavior, crack patterns, failure patterns, ductility, and ultimate strength of concrete beams with RCA contents ranging from 0 to $100 \%$ were investigated under flexure. The experimental data presented in this study provide valuable information for understanding the flexural strength and structural behavior of concrete beams containing RCAs.

\section{Material Properties}

3.1. Materials and Mixture Properties. Two types of coarse aggregates were used in this experimental setup, as shown in Figure 1 . The RCAs used in this study were obtained from the demolition of concrete structures, and accordingly, they did not include ceramic. The RCAs were produced by crushing waste concrete to a maximum size of $13 \mathrm{~mm}$, whereas the NCAs were produced by crushed stone to a maximum diameter of $25 \mathrm{~mm}$.

NCAs with a maximum size of $25 \mathrm{~mm}$ are commonly used in Korea. Therefore, the $25 \mathrm{~mm}$ NCAs were applied in this study. The RCAs were obtained by demolishing existing aged concrete structures and crushing the concrete, which reduced the size of the RCAs. In Korea, the maximum size of RCAs is usually less than $18 \mathrm{~mm}$. The effect of the coarse aggregate size on the mechanical properties of RCA concrete was investigated in the study by Meddah et al. [22]. This study showed that concrete mixtures with small RCAs (3-15 mm) had $1.8 \%$ higher compressive strength than the concrete mixtures with large RCAs (15-25 mm). Therefore, the size effect of the RCAs on the strength of the RCA concrete was not considered in this study.

Natural sand was used as the fine aggregates. The properties of the coarse aggregates, including the even-dry density (or specific gravity), absorption, and maximum diameter, are shown in Table 1. As expected, the RCAs had a lower specific gravity and higher absorption than the NCAs.

The mixture proportions for the test beams containing RCAs and NCAs are given in Table 2. The volume of NCAs in the mixtures was replaced by RCAs at three different replacement ratios: $30 \%, 50 \%$, and $100 \%$. The concrete mixtures had a target compressive strength of $35 \mathrm{MPa}$. Portland cement was used in the concrete mixture. The water-to-cement $(w / c)$ ratio was 0.38 . In addition, for this experiment, a high-range water reducer (HRWR) was used to control the workability of the concrete.

3.2. Mechanical Properties of the Materials. The compressive strength of the concrete was obtained through compressive testing of cylindrical specimens with diameters of $100 \mathrm{~mm}$ and heights of $200 \mathrm{~mm}$. When the test beams were fabricated, cylindrical specimens were fabricated with each batch.

Two types of compression test shapes are normally used: cubes and cylinders. Cylinders are the standard specimens used in the United States [23] and Korea [24]. According to KS F 2405 [24], the standard cylindrical specimen has dimensions of $100 \mathrm{~mm} \times 200 \mathrm{~mm}$ or $150 \mathrm{~mm} \times 300 \mathrm{~mm}$, and the diameter of the cylinders must be greater than three times the maximum size of the coarse aggregates.

A cylinder with dimensions of $100 \mathrm{~mm} \times 200 \mathrm{~mm}$ was selected for this study because the maximum size of the coarse aggregates used in this study was $25 \mathrm{~mm}$. To calculate the compressive strength of a cylinder with a diameter of $150 \mathrm{~mm}$, a correction factor of 0.97 should be multiplied to the compressive strength of a cylinder with a $100 \mathrm{~mm} \mathrm{di-}$ ameter [25].

The samples were loaded with a universal testing machine operating in displacement control mode. The axial deformations of the cylinders were measured accurately from the initiation of loading through failure. The load and the output from the three linear variable displacement transducers (LVDTs) were digitally recorded throughout the tests. 


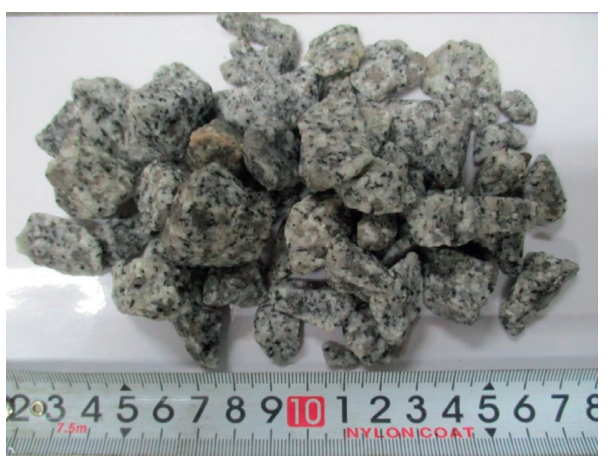

(a)

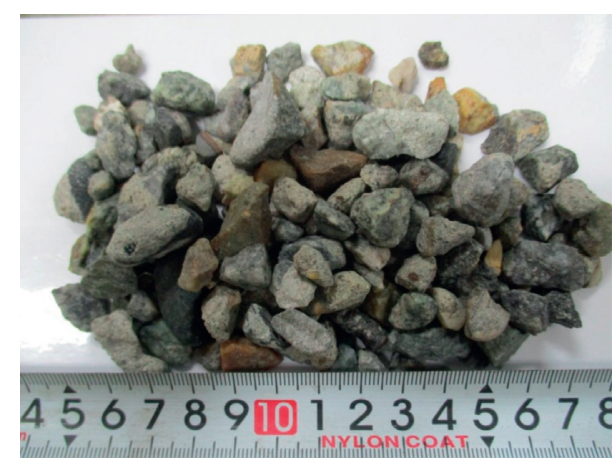

(b)

Figure 1: Coarse aggregates. (a) NCAs. (b) RCAs.

TABle 1: Properties of the coarse aggregates.

\begin{tabular}{lcccccc}
\hline & $\begin{array}{c}\text { Even-dry density } \\
\left(\mathrm{g} / \mathrm{cm}^{3}\right)\end{array}$ & $\mathrm{SD}\left(\mathrm{g} / \mathrm{cm}^{3}\right)$ & Absorption (\%) & $\mathrm{SD}(\%)$ & $\begin{array}{c}\text { Fineness } \\
\text { modulus }\end{array}$ & $\begin{array}{c}\text { Maximum diameter } \\
(\mathrm{mm})\end{array}$ \\
\hline $\begin{array}{l}\text { Recycled coarse } \\
\text { aggregate }\end{array}$ & 2.49 & 0.13 & 2.95 & 0.37 & 6.36 & 13 \\
Natural coarse aggregate & 2.62 & 0.17 & 0.57 & 0.11 & 6.55 & 25 \\
\hline
\end{tabular}

SD: standard deviation.

TABle 2: Mix proportions for the test beams.

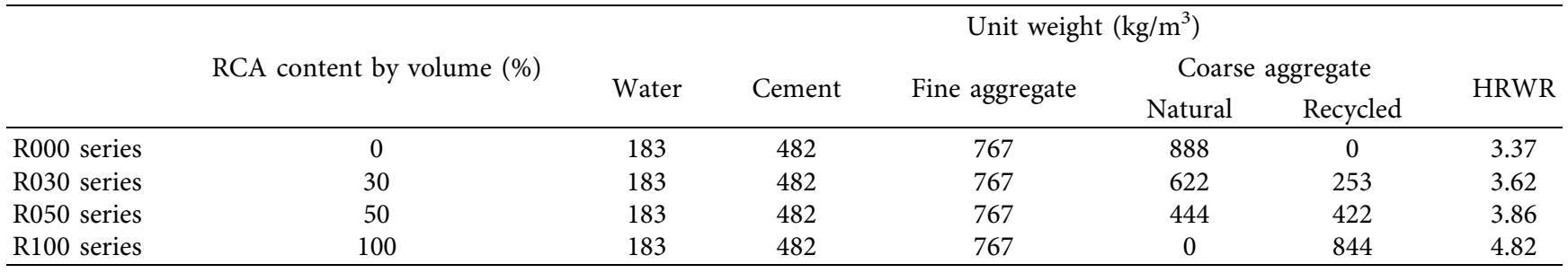

The stress-strain curve of each batch of concrete was obtained based on the load-displacement relationship measured during the test, which was subsequently used to compute the compressive strength and elastic modulus. The mean values of the compressive strength and the elastic modulus of each concrete beam are listed in Table 3. The test results show that the compressive strength and elastic modulus of the concrete decreased as the RCA content increased. However, the decrease in the rupture modulus of the concrete was not significant, when the RCA content increased to $50 \%$, whereas the decrease in the rupture modulus became significant when the RCA content increased to $100 \%$.

In addition, although HRWR was used to ensure the workability of the RCA concrete mixture, the real watercement ratio in each mixture might not be maintained due to the high water absorption from the RCAs. Accordingly, the mechanical properties of the RCA concrete may be affected.
For each test beam, two D13 (nominal diameter $=13 \mathrm{~mm}$ ), two D16 (nominal diameter $=16 \mathrm{~mm}$ ), or two D19 (nominal diameter $=19 \mathrm{~mm}$ ) reinforcing bars were used as tensile reinforcement. For each size, yield strength values of $516.3 \mathrm{MPa}, 434.9 \mathrm{MPa}$, and $517.5 \mathrm{MPa}$ were obtained from the rebar tension test. In addition, the ultimate strains at the peak stress for each rebar size were 0.0192, 0.0212, and 0.0136 .

\section{Test Program}

4.1. Beam Specimen Design. Twelve concrete beams were tested, the experimental parameters of which are listed in Table 3. All beams had rectangular cross sections with widths of $200 \mathrm{~mm}$ and heights of $300 \mathrm{~mm}$. The test parameters in the experiment were the RCA content and tensile rebar ratio. Three RCA contents $(30 \%, 50 \%$, and $100 \%)$ and three tensile reinforcement ratios $(0.50 \%, 0.79 \%$, and $1.14 \%)$ were adopted in this study. 
TABLE 3: Concrete properties and experimental parameters of the test beams.

\begin{tabular}{|c|c|c|c|c|c|c|c|c|c|}
\hline \multirow{2}{*}{$\begin{array}{l}\text { Test } \\
\text { beam }\end{array}$} & \multicolumn{6}{|c|}{ Concrete properties } & \multicolumn{3}{|c|}{ Experiment parameters } \\
\hline & $\begin{array}{l}\text { Compressive } \\
\text { strength }(\mathrm{MPa})\end{array}$ & $\begin{array}{l}\mathrm{SD} \\
(\mathrm{MPa})\end{array}$ & $\begin{array}{c}\text { Elastic } \\
\text { modulus (MPa) }\end{array}$ & $\begin{array}{c}\mathrm{SD} \\
(\mathrm{MPa})\end{array}$ & $\begin{array}{c}\text { Rupture } \\
\text { modulus (MPa) }\end{array}$ & $\begin{array}{l}\mathrm{SD} \\
(\mathrm{MPa})\end{array}$ & $\begin{array}{c}\text { RCA } \\
\text { content }(\%)\end{array}$ & $\begin{array}{c}\text { Tensile } \\
\text { rebar size }\end{array}$ & $\begin{array}{c}\text { Rebar } \\
\text { ratio (\%) }\end{array}$ \\
\hline R000-S1 & & & & & & & & $2 \times \mathrm{D} 13$ & 0.50 \\
\hline R000-S2 & 38.3 & 1.5 & 22,685 & 836 & 4.7 & 0.8 & 0 & $2 \times \mathrm{D} 16$ & 0.79 \\
\hline R000-S3 & & & & & & & & $2 \times \mathrm{D} 19$ & 1.14 \\
\hline R030-S1 & & & & & & & & $2 \times \mathrm{D} 13$ & 0.50 \\
\hline R030-S2 & 35.6 & 0.5 & 21,890 & 431 & 4.6 & 1.1 & 30 & $2 \times \mathrm{D} 16$ & 0.79 \\
\hline R030-S3 & & & & & & & & $2 \times \mathrm{D} 19$ & 1.14 \\
\hline R050-S1 & & & & & & & & $2 \times \mathrm{D} 13$ & 0.50 \\
\hline $\mathrm{R} 050-\mathrm{S} 2$ & 33.2 & 2.1 & 20,661 & 336 & 4.4 & 0.6 & 50 & $2 \times \mathrm{D} 16$ & 0.79 \\
\hline R050-S3 & & & & & & & & $2 \times \mathrm{D} 19$ & 1.14 \\
\hline R100-S1 & & & & & & & & $2 \times \mathrm{D} 13$ & 0.50 \\
\hline $\mathrm{R} 100-\mathrm{S} 2$ & 31.7 & 0.9 & 18,915 & 501 & 3.9 & 0.7 & 100 & $2 \times \mathrm{D} 16$ & 0.79 \\
\hline R100-S3 & & & & & & & & $2 \times \mathrm{D} 19$ & 1.14 \\
\hline
\end{tabular}

SD: standard deviation.

The test beams in Table 3 were named to indicate the RCA content and tensile rebar ratios. The three different tensile reinforcement ratios, $0.50 \%, 0.79 \%$, and $1.14 \%$, were denoted as S1, S2, and S3, respectively. For example, R050-S2 indicates that the beam has an RCA content of $50 \%$ and a tensile rebar ratio of $0.79 \%$. R000 series beams are reference beams containing no RCAs. Four groups of test beams with different RCA contents were studied, and each group contained three beams with different rebar ratios.

For all beams, transverse reinforcements were provided to prevent shear failure. Stirrups with nominal diameters of $10 \mathrm{~mm}$ (D10) were used for transverse reinforcement, but no stirrups were used in the constant moment region to avoid the confinement effect on the flexural behavior. Two top rebars with a nominal diameter of $10 \mathrm{~mm}$ were used to hold the stirrups. The test beam dimensions are shown in Figure 2.

4.2. Fabrication of the Beam Specimens. Steel molds were used to fabricate the beam specimens. After assembling the forms, the rebar was arranged, and the rebar strain gauges were installed in the midspan to measure the strain in the tensile rebar at each loading step during the test.

After pouring, the concrete was compacted using vibration. The beam specimens were covered with both wet burlap and plastic sheets upon completion of the concrete casting. All beams and companion concrete cylinders were moist-cured for seven days. The beam specimens were then demolded and air-cured until 28 days after the concrete was poured.

4.3. Test Setup and Instrumentation. The beams were tested under simply supported four-point loading conditions, as shown in Figure 3. The total length of each test beam was $3.3 \mathrm{~m}$, and the simple supports were located $150 \mathrm{~mm}$ from each end of the beam; that is, the clear span length was $3.0 \mathrm{~m}$. A steel spreader beam was installed between the test beam specimen and the actuator to distribute the single point load into two point loads. The two loads were applied $300 \mathrm{~mm}$ from the midspan through the steel spreader beam. Therefore, the shear span of each beam was $1.2 \mathrm{~m}$, and the constant moment region was the center $0.6 \mathrm{~m}$ of the beam.

The instrumentation system shown in Figure 4 consisted of LVDTs and electrical resistance strain gauges. Electrical resistance strain gauges were used to measure the strain in the concrete and the steel rebar. Five strain gauges were located on the side surface of the beam in the midspan to measure the strain at different heights. These strain gauges were mounted on the surface of the rear side of the beam specimen. The length of the strain gauges mounted on the concrete was $60 \mathrm{~mm}$. Individual gauges were used until their readings became unreliable due to cracking in the underlying concrete. They were able to detect strain from small crack openings at each location. However, the concrete strain gauges became unreliable as the crack width increased. Three steel strain gauges were bonded to each tensile rebar in the beam midspan. In addition, the LVDTs were placed in the midspan and at the loading points to measure the beam deflections.

The load was applied to the beams using hydraulic jacks. Each beam test was conducted at a crosshead displacement rate of $1.5 \mathrm{~mm} / \mathrm{min}$. The test was performed until beam failure. The applied load, deflection, and strain in both the concrete and the rebar, the development and propagation of cracks, and the width of each crack were recorded until beam failure.

4.4. Calculating the Ductility and Flexural Strength of the Concrete Beams. The ductility of a concrete structure can be interpreted as a measure of the energy absorption capacity of the structural member. In general, the ductility of a concrete structure can be quantified via the ductility index, which can be expressed in terms of the deflection ductility index [26]. Midspan deflection measurements are necessary only for the deflection ductility index, and its measurement is relatively easy. The deflection ductility index, shown in (1), was used to 
[Unit: $\mathrm{mm}$ ]

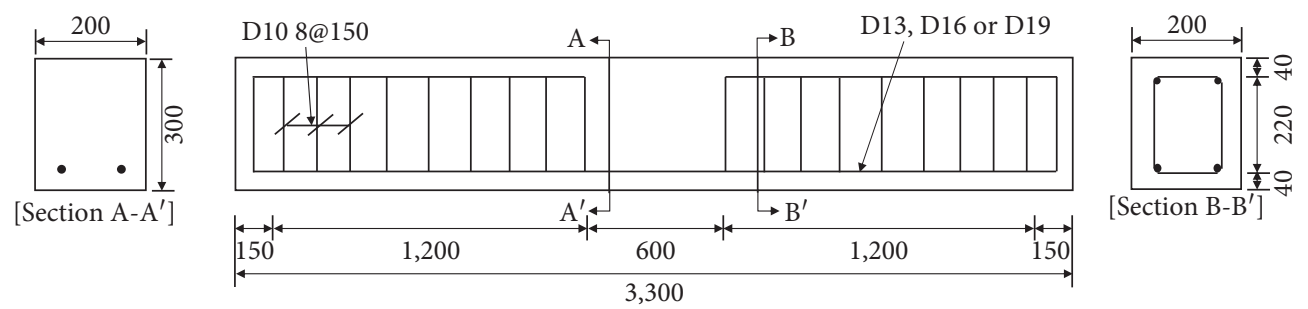

Figure 2: Test beam dimensions.

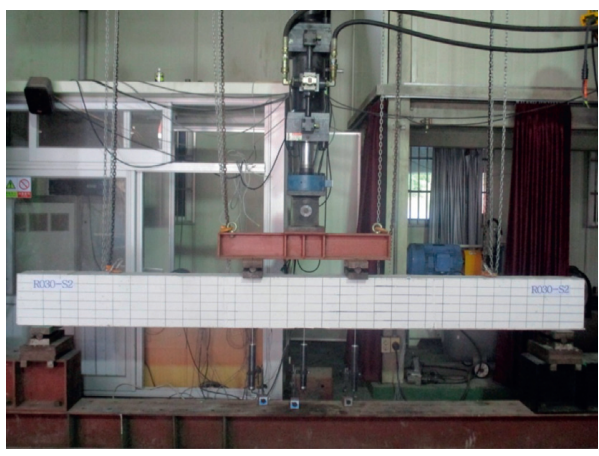

FIGURE 3: Test setup for the beam specimens.

examine the ductility characteristics of the members as follows:

$$
\mu=\frac{\Delta_{u}}{\Delta_{y}},
$$

where $\mu$ is the ductility index of the member, $\Delta_{u}$ is the deflection of the member at the ultimate load, and $\Delta_{y}$ is the deflection of the member at the yielding load. The deflection at the ultimate load corresponds to the peak point in the load-deflection curve.

For the flexural strength of the concrete beams, the experimental results were compared with the calculations from the ACI 318 flexural design provision [27], EC 2 provision [28], and modified compression field theory (MCFT) using the Response 2000 program $[29,30]$. The ACI 318 flexural design provision [27] is as follows:

$$
\begin{aligned}
M_{n} & =A_{s} f_{y}\left(d-\frac{a}{2}\right), \\
a & =\frac{A_{s} f_{y}}{0.85 f_{c}^{\prime} b},
\end{aligned}
$$

where $A_{s}$ is the area of the tensile rebar, $f_{y}$ is the measured yield strength of the rebar, $d$ is the effective depth, $a$ is the depth of an equivalent rectangular compressive stress block, $f_{c}^{\prime}$ is the concrete measured compressive strength, and $b$ is the width of a rectangular beam.

The EC 2 provision [28] for flexural capacity is as follows:

$$
\begin{aligned}
M_{n} & =T z=T \cdot\left(d-\frac{a}{2}\right), \\
T & =A_{s} f_{y d}, \\
a & =\frac{A_{s} f_{y d}}{\eta f_{c d} b}, \\
f_{c d} & =\frac{\alpha_{c c} f_{c k}}{\gamma_{c}}, \\
f_{y d} & =\frac{f_{y}}{\gamma_{s}},
\end{aligned}
$$

where $T$ is the tensile force on the rebar, $f_{y d}$ is the design yield strength of the rebar, $f_{y}$ is the measured yield strength of the rebar, $f_{c d}$ is the design value of the concrete compressive strength, $f_{c k}$ is the measured concrete compressive strength, $\gamma_{c}$ is the partial safety factor for the concrete, $\gamma_{s}$ is the partial safety factor for the rebar, and $\alpha_{c c}$ is a coefficient $(=0.85$ in this study) that considers the long-term effects on the compressive strength and the unfavorable effects resulting from the way the load is applied.

To calculate the nominal flexural strength of the NCA and RCA concrete beams as accurately as possible, $\gamma_{c}$ and $\gamma_{s}$ are assumed to be 1.0. For the design of concrete structures, the selected values of the partial safety factors, $\gamma_{c}$ and $\gamma_{s}$, are less than 1.0 to ensure the structural safety of the concrete structures. However, these values are set to 1.0 in this study to predict the actual flexural strength of the test beams.

The Response 2000 program incorporating the MCFT is a sectional analysis program that can calculate the strength of a reinforced concrete cross section subjected to shear, flexure, and axial loading [30].

\section{Test Results and Discussion}

5.1. Crack and Failure Patterns. Measurements of the crack and failure patterns of the beams were performed. In addition, measurements of the propagation of the cracks were performed at each loading step. At the initial cracking stage, the RCA concrete beams exhibited a higher number of cracks than the control beam, as shown in Figure 5. This phenomenon might occur because the interfacial transition 


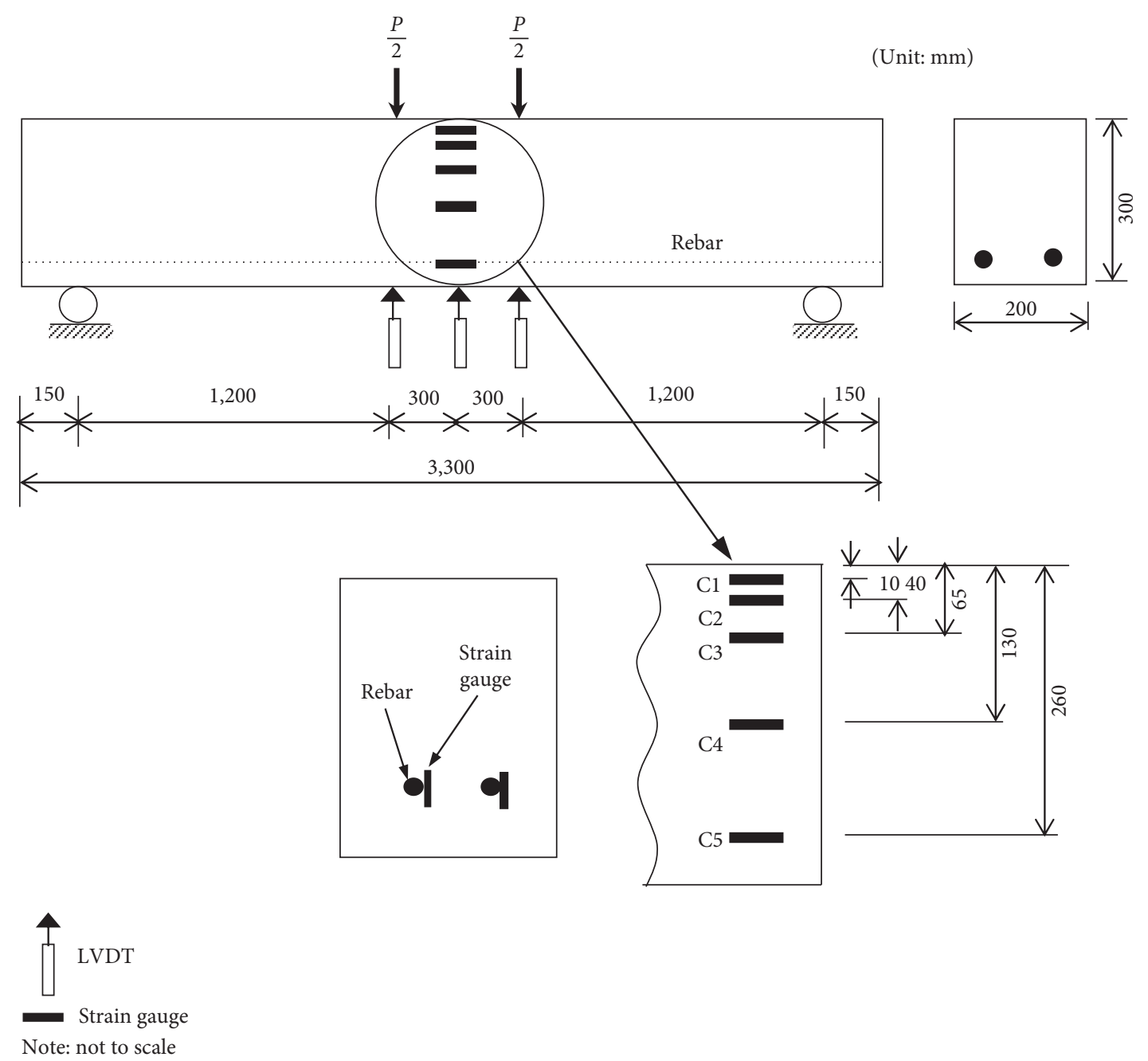

Figure 4: Instrumentation system.

zone between the RCAs and paste was weaker than that between the NCAs and paste. The weak interfacial transition zone in the RCA concrete was due to residual mortar on the surface of the RCAs.

The crack patterns of the S1 series beams in the service loading stage are shown in Figure 6 . The load corresponding to $60 \%$ of the rebar yield strength was considered a typical service load. The crack propagation of the RCA beams was similar to that of the control beam. After the initial cracking stage, new cracks occurred inside and outside the constant bending zone in both NCA and RCA beams as the load increased. These new and existing cracks propagated up to the compressive zone until failure occurred in both types of beams. However, the number of cracks in the RCA beams was higher than that in the control beam.

In addition, the crack patterns at failure for the S1 series beams are shown in Figure 7. The overall crack patterns of both NCA and RCA beams were similar to experimental results reported in the study of Sera-Paz et al. [15]. The RCA beams generally sustained more cracks than the NCA beams. Hence, the crack spacing was closer in the RCA beams than in the NCA beams. According to the studies by Sunayana and Barai [16] and Sturm et al. [31], the closer cracking spacing in the RCA beams might be due to the effect of high shrinkage in the RCA beams.

All test beams failed in flexure. The test results indicate that the tensile cracks occurred first, and then the tensile rebar yielded, followed by concrete crushing, which is usually referred to as tension failure. Cracks did not appear at the beginning of the test, during which the load increased linearly. The first cracks occurred on the bottom face of the beam between the loading points, where the beam was subjected to pure bending. The cracks propagated toward the upper face. As the load increased after the initial cracking, additional flexural cracks formed between the load and supports. As the applied load was further increased, most of the flexural cracks developed vertically, and subsequently, inclined flexure-shear cracks began to appear.

The relation of the load to the crack width for each beam series is shown in Figure 8. For each beam series, the beams had the same rebar ratio but different RCA contents. For series S1, the crack widths of the RCA and NCA beams up to the rebar yield point were similar. For series S2, the crack widths of the RCA and NCA beams up to the rebar yield point were similar except for beam R050-S2. The crack width of beam R05-S2 was slightly larger than that of the other 


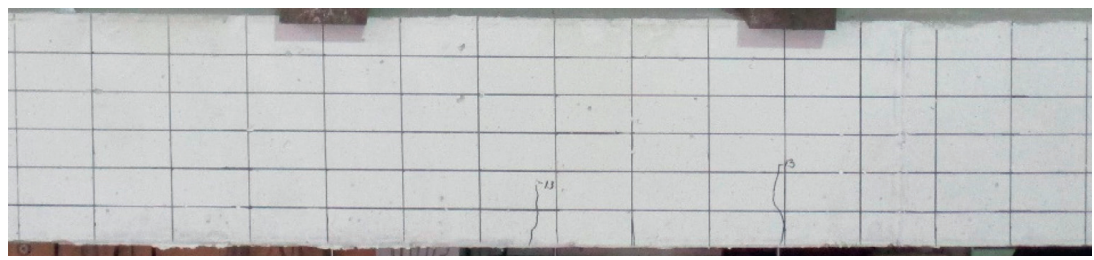

(a)

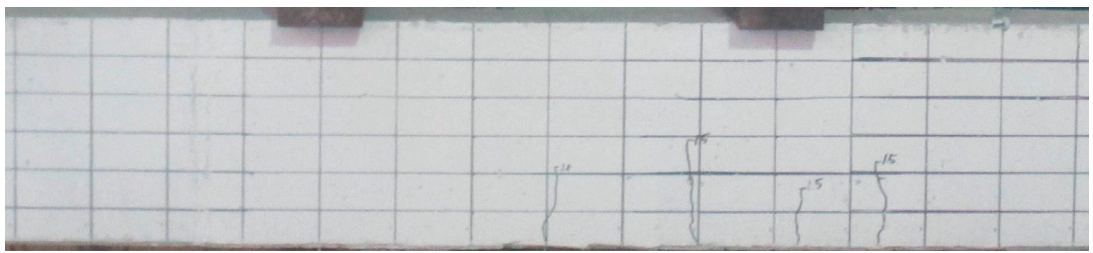

(b)

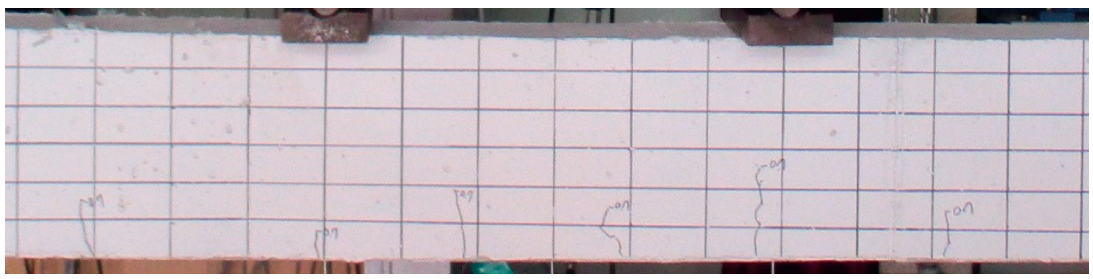

(c)

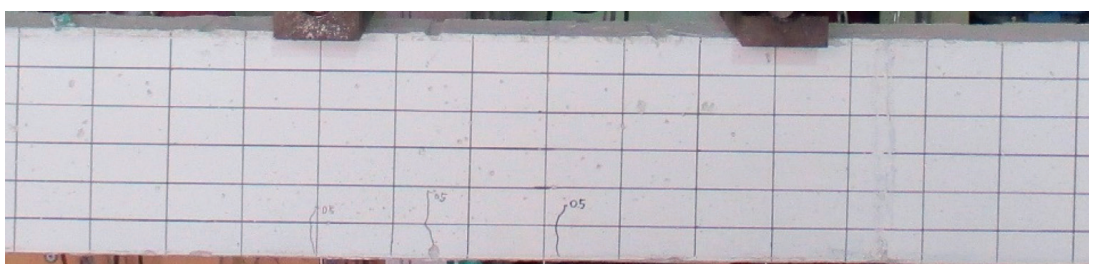

(d)

Figure 5: Typical crack patterns at the initial cracking stage $\left(P=P_{c r}\right)$ (S2 series beams). (a) Beam R000-S2. (b) Beam R030-S2. (c) Beam R050-S2. (d) Beam R100-S2.

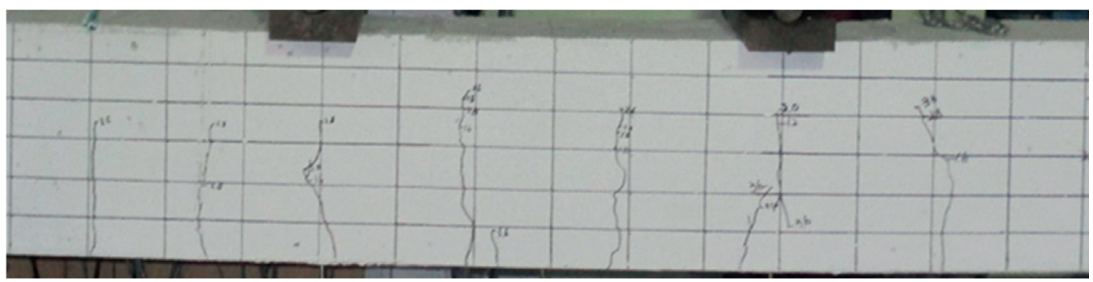

(a)

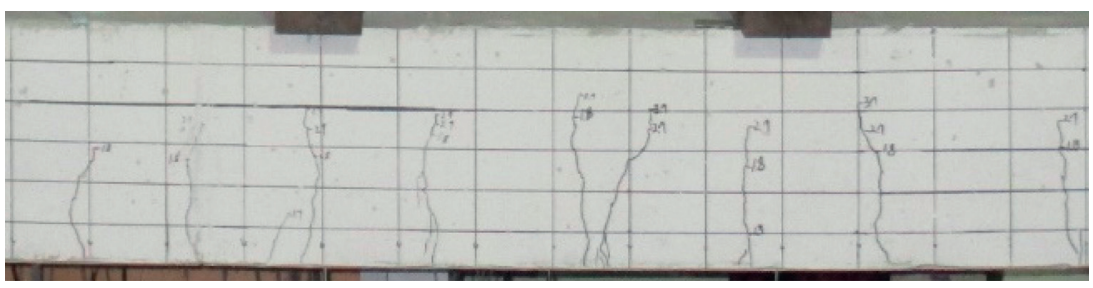

(b)

Figure 6: Continued. 


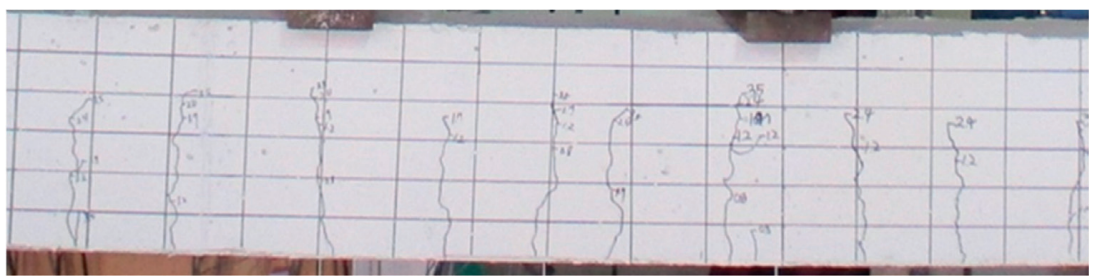

(c)

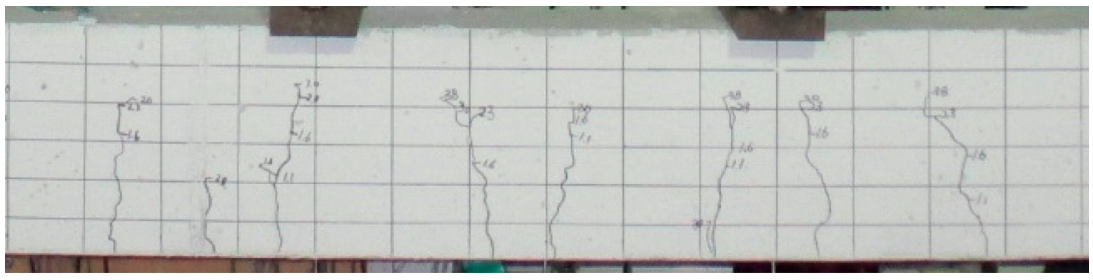

(d)

Figure 6: Typical crack patterns at the service load stage ( $P=0.6 P_{y}, \mathrm{~S} 1$ series beams). (a) Beam R000-S1. (b) Beam R030-S1. (c) Beam R050-S1. (d) Beam R100-S1.

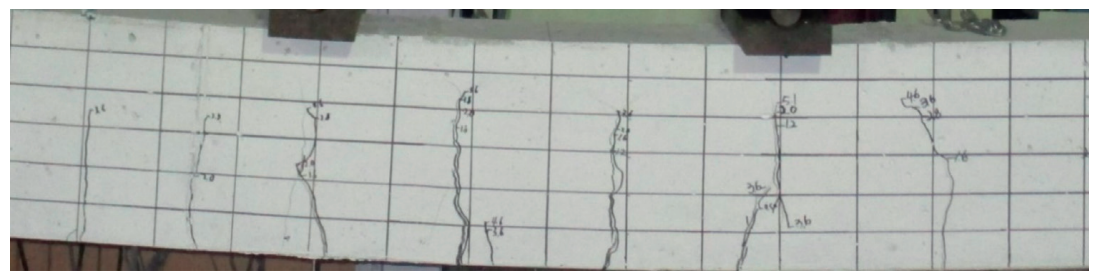

(a)

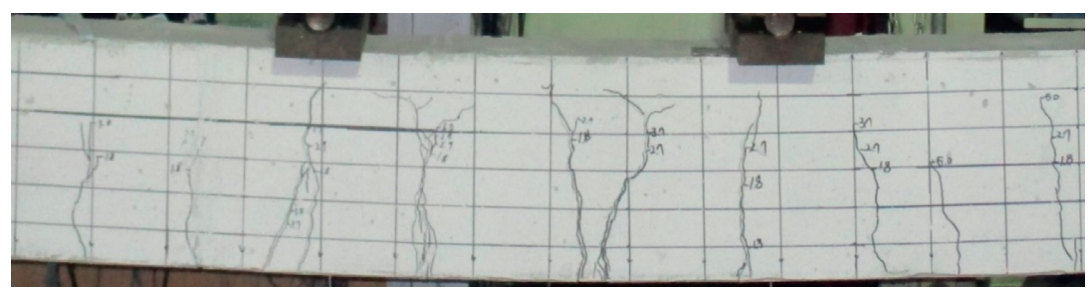

(b)

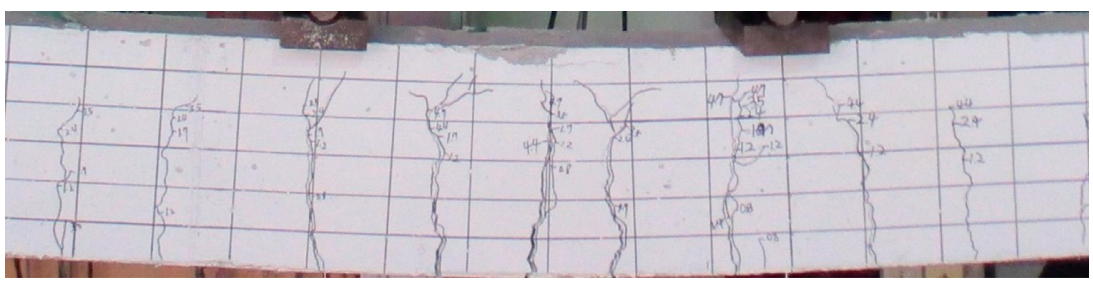

(c)

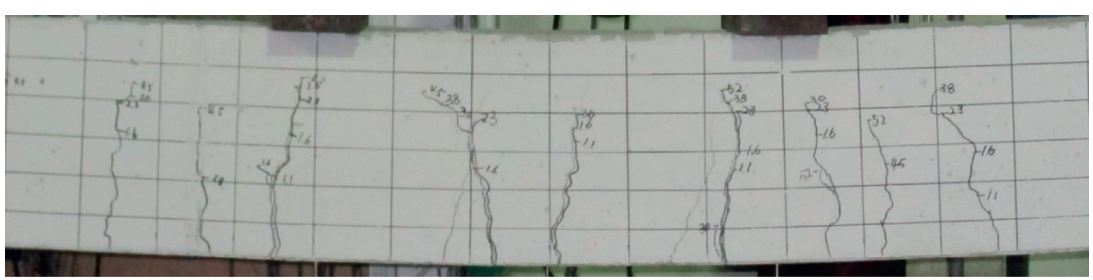

(d)

Figure 7: Typical crack failure patterns (S1 series beams). (a) Beam R030-S1. (b) Beam R030-S1. (c) Beam R050-S1. (d) Beam R100-S1. 
beams. For series S3, the crack widths of the RCA and NCA beams up to the rebar yield point were similar except for beam R100-S3. The crack width of beam R100-S3 was slightly larger than that of the other beams.

Finally, the test results indicate that the number of cracks in the RCA beams was greater than that in the NCA beams and that the crack widths were similar in the RCA and NCA beams.

5.2. Load-Deflection Relationship. The load-deflection curves of the beams, measured at each loading step by the LVDTs installed in the midspan of the beams, are shown in Figures 9 and 10. Table 4 shows the first cracking load, the yield load, and the ultimate load for each specimen.

The first cracking load is the value of the load at the end of the initial linear zone in the load-deflection curve. The yield load is the load at which the rebar yielded, and the ultimate load is the maximum load of the load-deflection curve.

The deflection of the beam up to the point of crack initiation increased linearly and proportionally to the load. After the initial cracking began, each beam specimen showed nearly linear behavior until the tensile rebar yielded. From the yield point of the rebar, each beam specimen exhibited nonlinear behavior until failure.

The test results showed that the initial cracking load of the beam with $100 \%$ RCA content was lower than that of the control beam. The two lowest initial cracking loads were found in beams R100-S2 and R100-S3. This is likely because the RCA concrete has lower tensile strength than the NCA concrete. These test results are similar to those in the study by Arezoumandi et al. [19], which investigated the flexural behavior of RCA beams with an RCA content of $100 \%$. The lower cracking load of the RCA beams was related to the interfacial transition zones between the RCAs and cement paste, which is weaker than that of the NCA beams.

The load-deflection curves for the control concrete beam and RCA concrete beams $(30 \%, 50 \%$, and $100 \%)$ with the same rebar ratio are shown in Figure 9. For series S1 and S2, the RCA content affected the ultimate load. As an example, the ultimate loads of beams R000-S2, R030-S2, R050-S2, and $\mathrm{R} 100-\mathrm{S} 2$ were $91.5,88.3,82.2$, and $81.0 \mathrm{kN}$, respectively. This indicates that the flexural ultimate strength decreased as the RCA content increased.

However, for the S3 series, the effect of the RCA content on the ultimate load was not significant. The tensile rebar ratios in the $\mathrm{S} 3$ series beams were higher than those in the S1 and S2 series beams. Therefore, in terms of the flexural strength, the S3 series beams may be controlled more by the tensile rebar than by the concrete strength.

The slopes of the load-deflection curves of the RCA beams were slightly less than those of the NCA beams. This finding indicates that the RCA content affected the stiffness of the concrete beams, which could be attributed to the RCA beams having a lower elastic modulus than the NCA beams. This could result from the decrease in bonding in the RCA beams.
The interfacial bonding between RCAs and mortar is known to be less substantial than that between NCAs and mortar [32].

To investigate the effects of the rebar ratio on the flexural strength, the load-deflection curves for beams with different rebar ratios are shown in Figure 10. As expected, the ultimate flexural strength increased as the rebar ratio increased. A comparison of the load-deflection curves of the beams with an RCA content of $50 \%$ is shown in Figure 10(c). The results show that the ultimate flexural strength values for beams with rebar ratios of $0.79 \%$ (R050-S2) and $1.14 \%$ (R050-S3) were $43.8 \%$ and $107.6 \%$ greater than that of a beam with a rebar ratio of $0.50 \%$ (R050-S1), respectively. In addition, the flexural stiffness of the beams after initial cracking increased as the rebar ratio increased.

5.3. Ductility. The ductility index for each beam is listed in Table 4. The ductility index ranged from 4.7 to 4.9 for beams with a rebar ratio of $0.50 \%$ (S1 series). The difference in the ductility index among the four beams in the S1 series was not remarkable. This result indicates that the ductility index was not affected significantly by the RCA content in the S1 series.

The ductility index ranged from 6.3 to 7.0 for beams with a rebar ratio of $0.79 \%$ (S2 series) and from 1.7 to 2.5 for beams with a rebar ratio of $1.14 \%$ (S3 series). This result also indicates that the ductility index was not affected significantly by the RCA content but was affected by the tensile rebar ratio for the S2 and S3 series.

5.4. Bending Moment versus Curvature. Strain gauge measurements were used to determine the curvature, and the planar sections were assumed to remain planar. The strain profile for the height of the beam could be used to compute the curvature of the cross section. Individual gauge measurements were used until their readings became unreliable due to cracking in the underlying concrete. The applied bending moment is plotted against the curvature in the midspan of the test beams in Figure 11. The curvature developed linearly up to approximately $0.17 \times 10^{-5} / \mathrm{mm}$, which corresponds to the initial cracking load.

The slopes of the bending moment-curvature curves between the initial cracking state and the yield state are less than they are between the origin and the initial cracking state; however, the slopes remain nearly linear. The slope of the bending moment-curvature curve between the initial cracking state and the yield state is the cracked stiffness.

For the $\mathrm{S} 1$ series, the cracked stiffness values of beams R030-S1 and R050-S1 were lower than that of beam R000-S1. For the S2 series, the cracked stiffness values of beams R030-S2 and R050-S2 were lower than that of beam R000-S2. For the S3 series, the cracked stiffness values of beams R030-S3, R050-S3, and R100-S3 were lower than that of beam R000-S3. These results indicate that, overall, the stiffness of the RCA beams was lower than that of the NCA beams. This also corresponds to the 


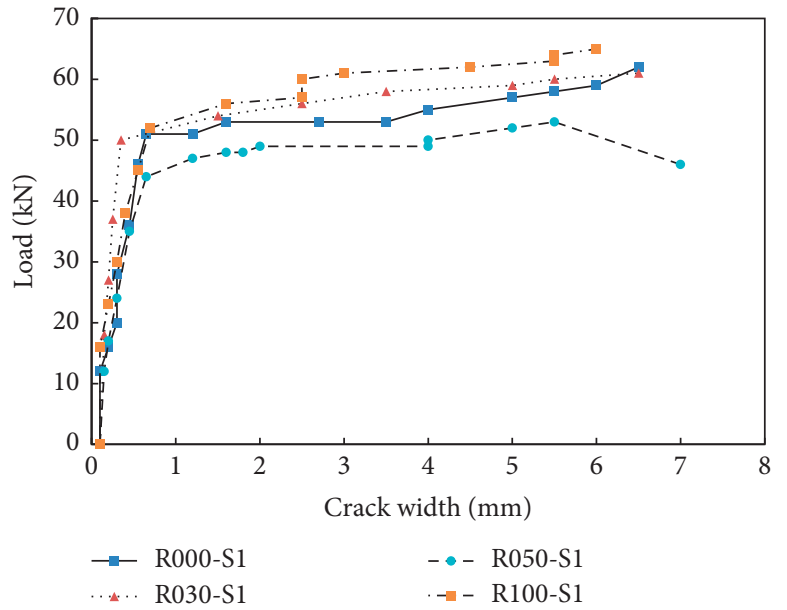

(a)

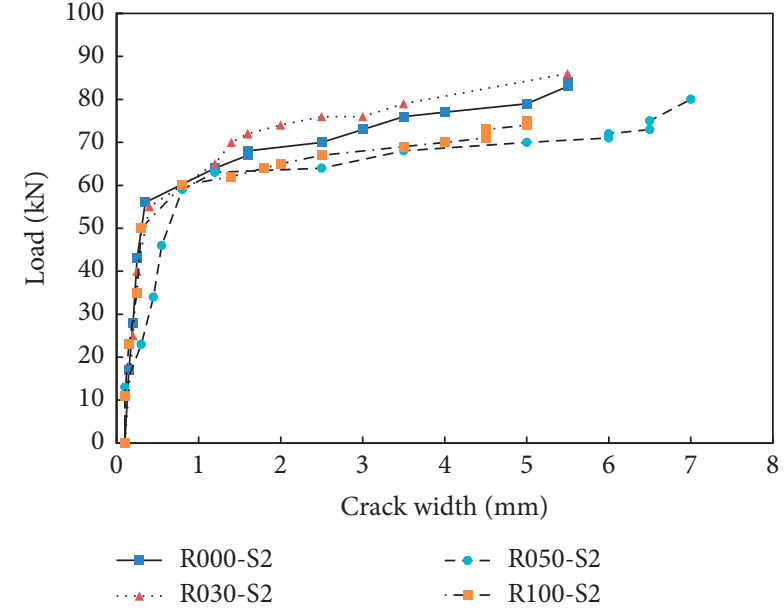

(b)

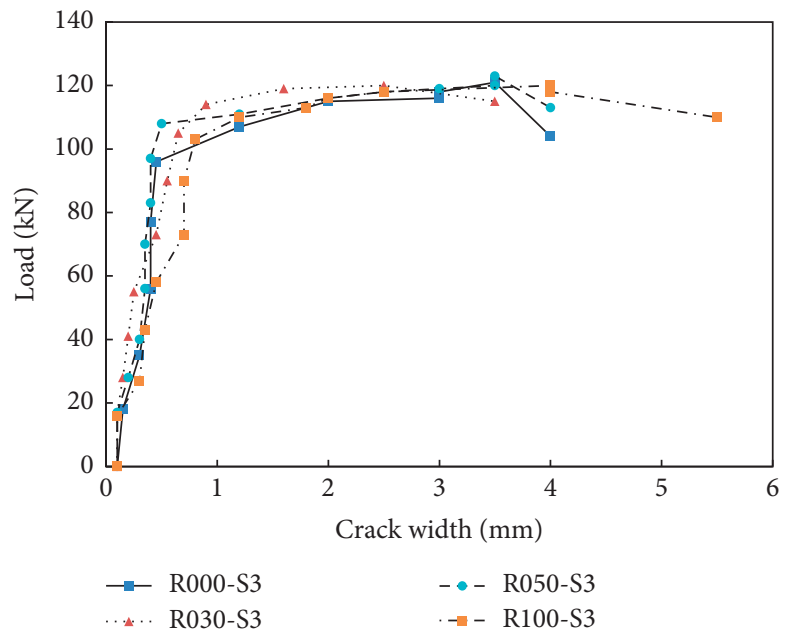

(c)

FiguRE 8: Load versus crack width. (a) S1 series beams (rebar ratio of 0.50\%). (b) S2 series beams (rebar ratio of 0.79\%). (c) S3 series beams (rebar ratio of $1.14 \%$ ).

fact that the slopes of the load-deflection curves of the RCA beams were slightly lower than those of the NCA beams.

5.5. Flexural Strength of RCA Concrete Beams. The experimental results and calculations for the nominal flexural strength are plotted in Figure 12. The measured flexural strength values of both NCA and RCA beams were greater than the nominal flexural strength values calculated by the ACI 318 provision and EC 2 provision.

The ACI 318 provision underestimated the experimental flexural strength for both NCA and RCA concrete beams. The ratio of the experimental flexural strength to the calculation from the ACI 318 provision ranged from 1.08 to 1.33 for the NCA concrete beams and from 1.09 to 1.30 for the RCA concrete beams.

The EC 2 provision also underestimated the experimental flexural strength. The calculation from the EC 2 provision is similar to that from the ACI 318 provision.
The study by Arezoumandi et al. [19] also revealed that the ACI 318 and EC2 provisions underestimated the flexural capacity for RCA beams by $5 \%$ to $14 \%$. Underestimating the flexural strength of RCA beams might occur because the tension stiffening effect was not considered when predicting the flexural strength with the ACI and EC2 provisions. Therefore, the ratio of the experimental results to the calculated results indicates that the current provisions conservatively predicted the flexural strength of the RCA concrete beams.

The ratio of the experimental flexural strength to the calculation from the MCFT ranged from 0.92 to 1.05 for NCA beams and from 0.88 to 1.09 for RCA beams. Overall, the MCFT method slightly overestimated the experimental flexural strength. This might be due to the difference between the effect of tension stiffening incorporated in the program and that in the actual RCA concrete beams. The Response 2000 program considers the effect of tension stiffening based on conventional concrete. 


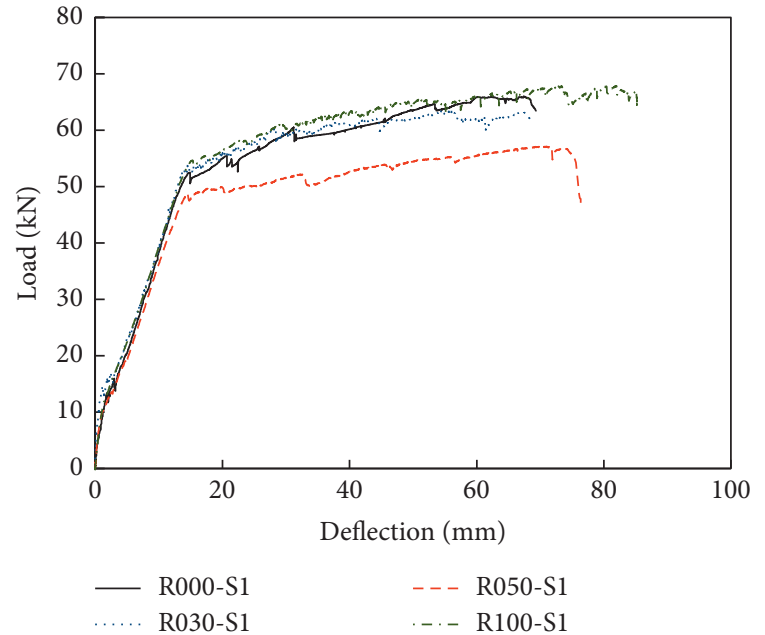

(a)

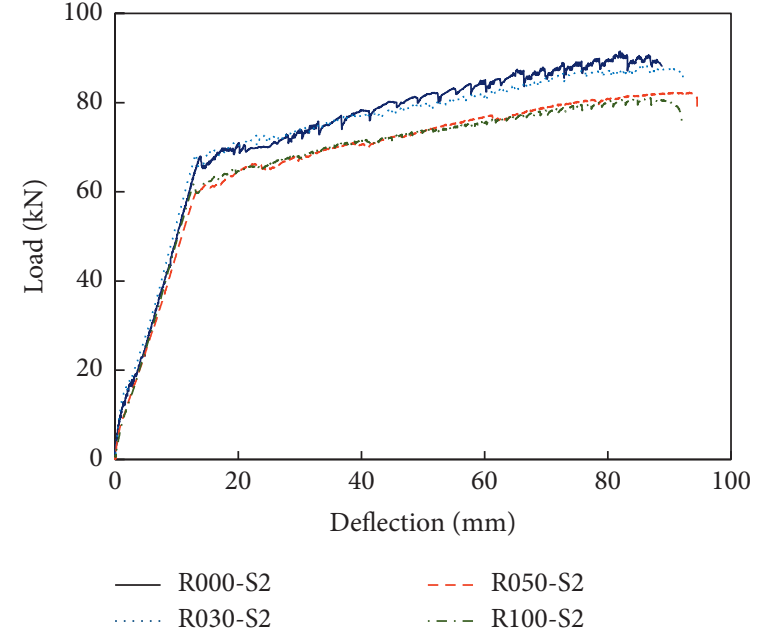

(b)

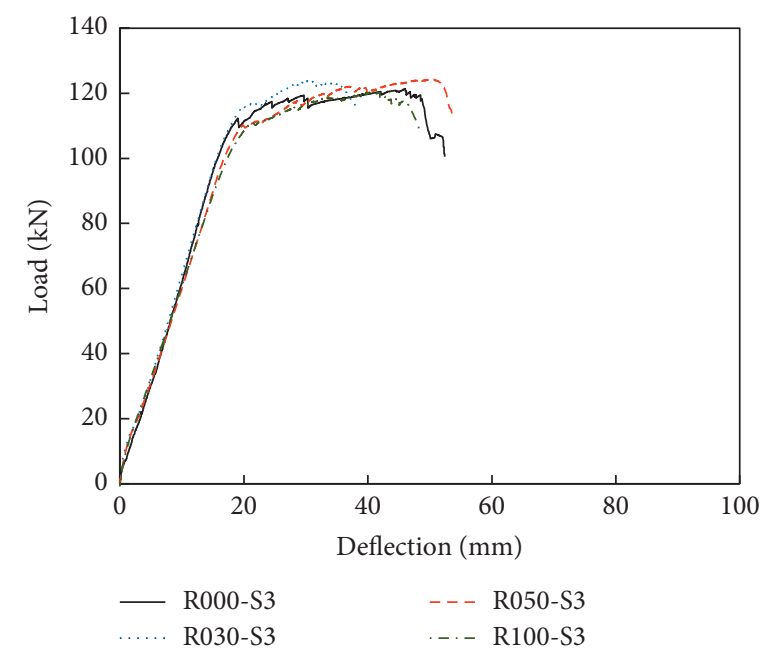

(c)

Figure 9: Effect of the RCA content on the load-deflection curves. (a) S1 series beams (rebar ratio of 0.50\%). (b) S2 series beams (rebar ratio of $0.79 \%$ ). (c) S3 series beams (rebar ratio of $1.14 \%$ ).

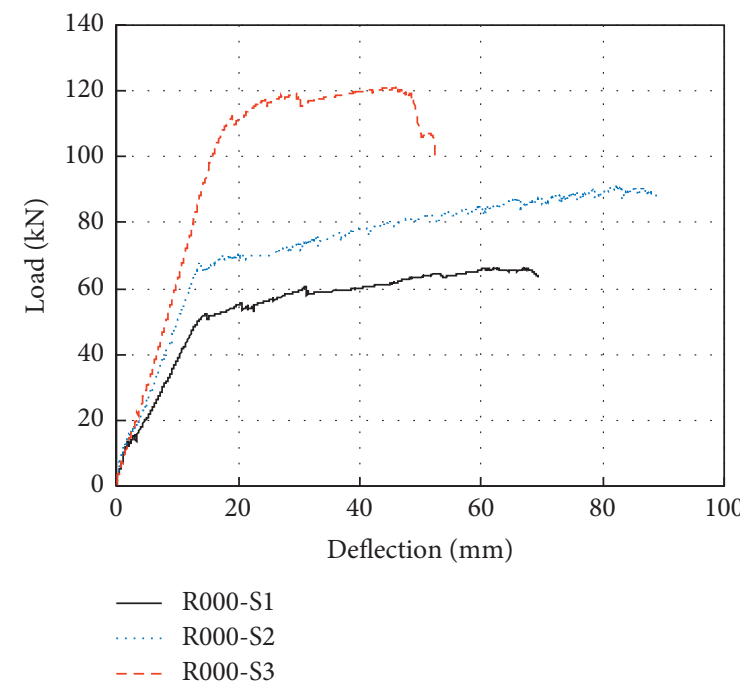

(a)

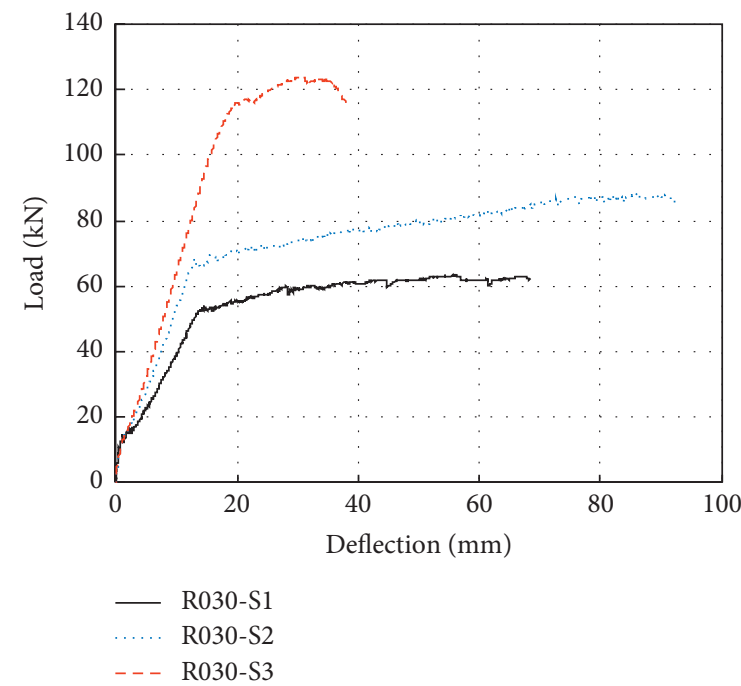

(b)

Figure 10: Continued. 


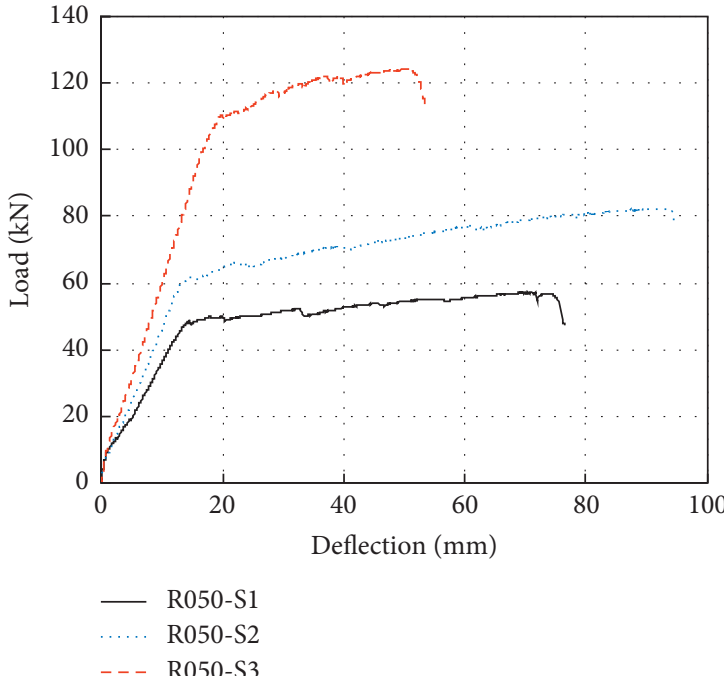

(c)

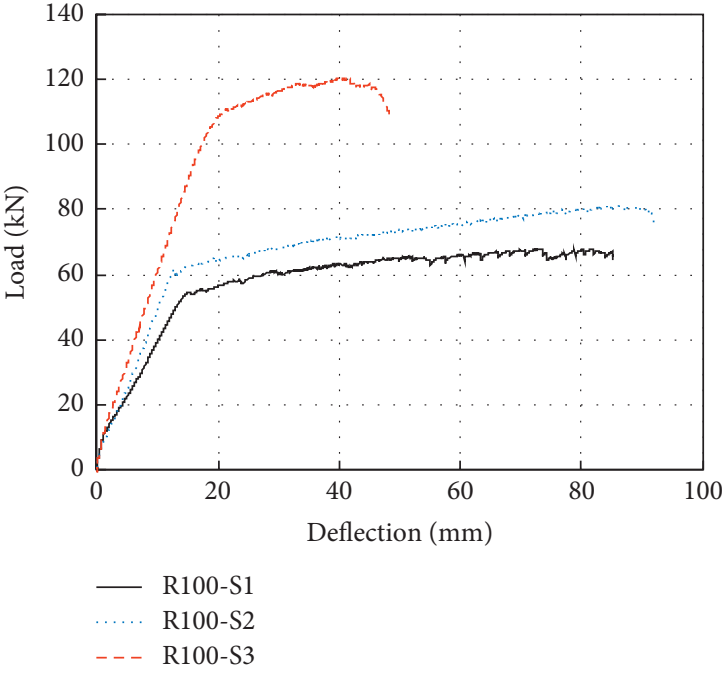

(d)

Figure 10: Effect of the rebar ratio on the load-deflection curves. (a) R000 series beams (control concrete). (b) R030 series beams (RCA content of 30\%). (c) R050 series beams (RCA content of 50\%). (d) R100 series beams (RCA content of 100\%).

TABLE 4: Experimental values of the cracking, yield, and ultimate loads.

\begin{tabular}{|c|c|c|c|c|c|c|c|}
\hline \multirow{2}{*}{ Beam specimen } & \multicolumn{2}{|c|}{ Initial cracking } & \multicolumn{2}{|c|}{ Yield state } & \multicolumn{2}{|c|}{ Ultimate state } & \multirow{2}{*}{$\begin{array}{l}\text { Ductility index } \\
\qquad \Delta_{u} / \Delta_{y}\end{array}$} \\
\hline & $P_{c r}(\mathrm{kN})$ & $\Delta_{c r}(\mathrm{~mm})$ & $P_{y}(\mathrm{kN})$ & $\Delta_{y}(\mathrm{~mm})$ & $P_{u}(\mathrm{kN})$ & $\Delta_{u}(\mathrm{~mm})$ & \\
\hline R000-S1 & 13.4 & 1.90 & 52.5 & 14.9 & 66.3 & 90.3 & 4.7 \\
\hline R000-S2 & 13.0 & 1.50 & 68.0 & 13.8 & 91.5 & 96.8 & 6.4 \\
\hline R000-S3 & 7.2 & 0.80 & 112.4 & 19.0 & 121.5 & 46.0 & 2.4 \\
\hline R030-S1 & 14.7 & 1.10 & 53.9 & 14.5 & 65.2 & 86.3 & 4.7 \\
\hline R030-S2 & 16.1 & 1.84 & 68.5 & 13.1 & 88.3 & 92.2 & 7.0 \\
\hline R030-S3 & 15.3 & 1.63 & 115.9 & 20.0 & 123.7 & 34.9 & 1.7 \\
\hline R050-S1 & 10.0 & 1.12 & 48.7 & 14.5 & 57.1 & 70.9 & 4.9 \\
\hline R050-S2 & 8.9 & 1.13 & 61.6 & 14.7 & 82.2 & 93.5 & 6.3 \\
\hline R050-S3 & 11.9 & 1.18 & 110.2 & 19.8 & 124.3 & 50.3 & 2.5 \\
\hline R100-S1 & 11.9 & 1.39 & 54.7 & 15.2 & 67.9 & 73.3 & 4.8 \\
\hline R100-S2 & 5.0 & 0.60 & 61.9 & 12.9 & 81.0 & 84.7 & 6.6 \\
\hline R100-S3 & 5.9 & 0.50 & 110.9 & 21.5 & 120.4 & 41.2 & 1.9 \\
\hline
\end{tabular}

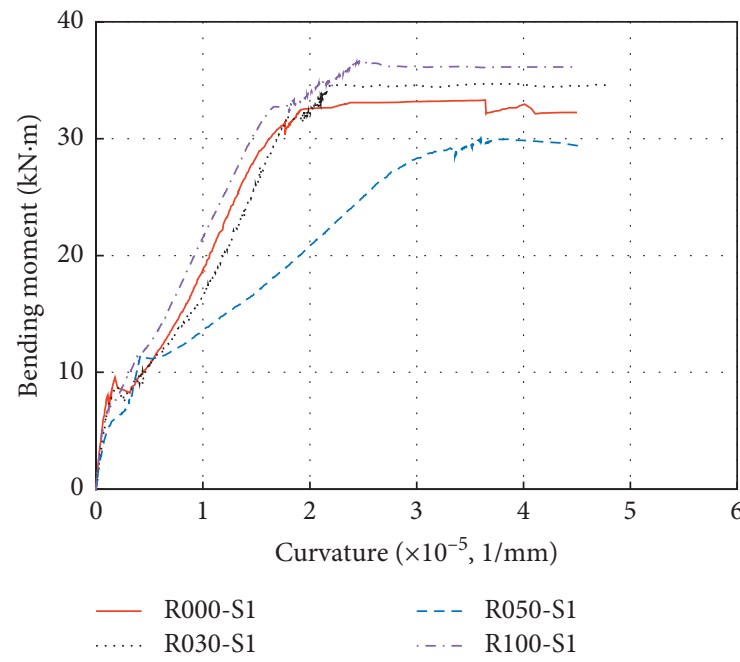

(a)

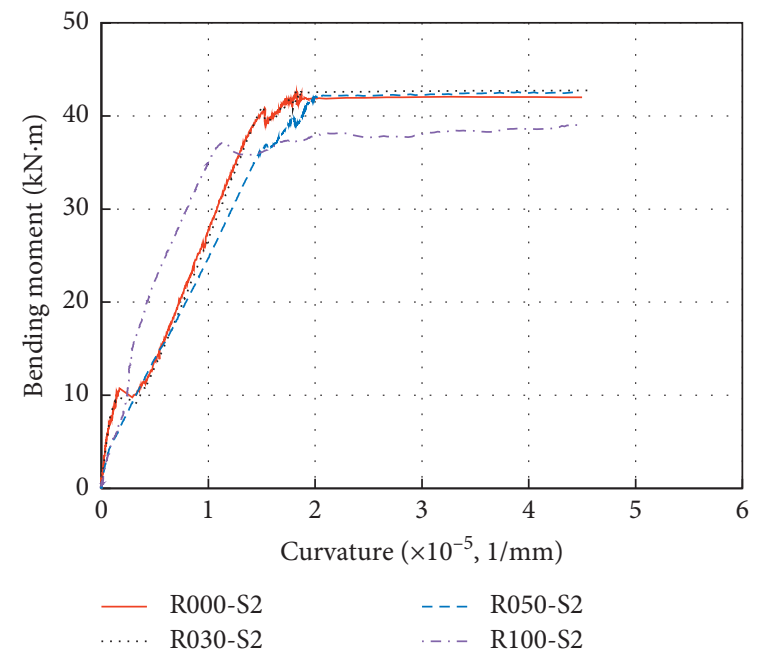

(b)

Figure 11: Continued. 


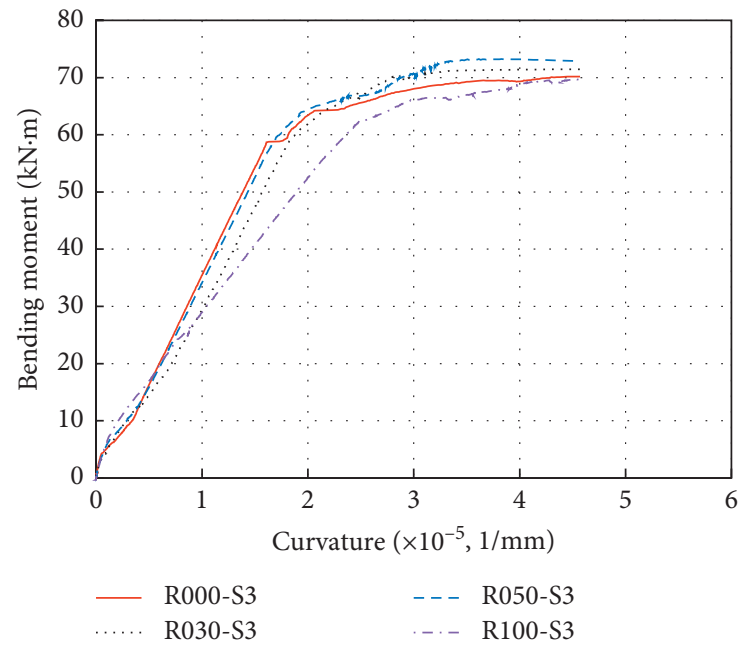

(c)

Figure 11: Bending moment versus curvature. (a) Beams with a rebar ratio of $0.50 \%$. (b) Beams with a rebar ratio of $0.79 \%$. (c) Beams with a rebar ratio of $1.14 \%$.

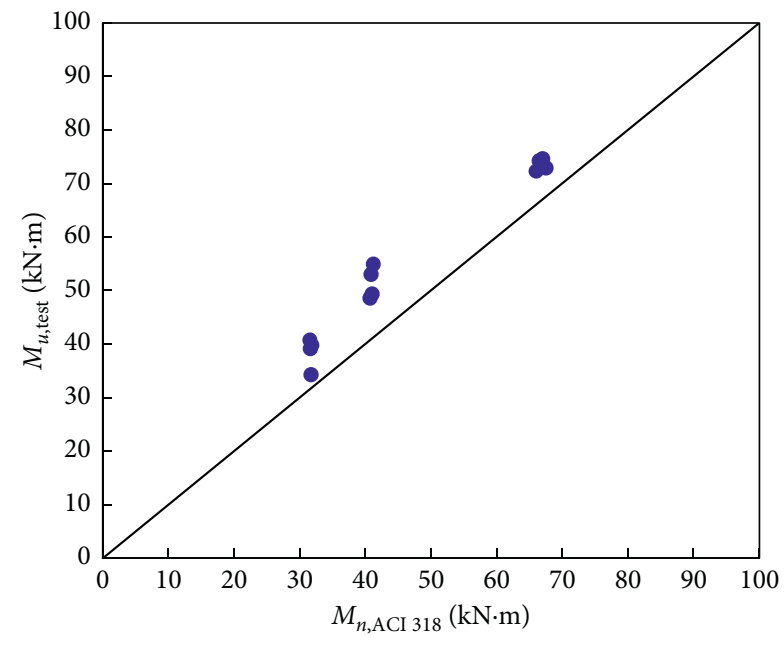

(a)

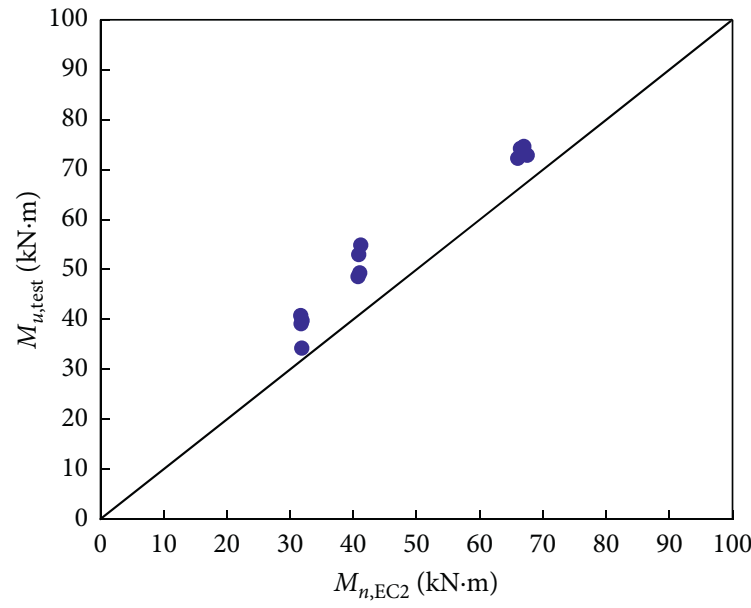

(b)

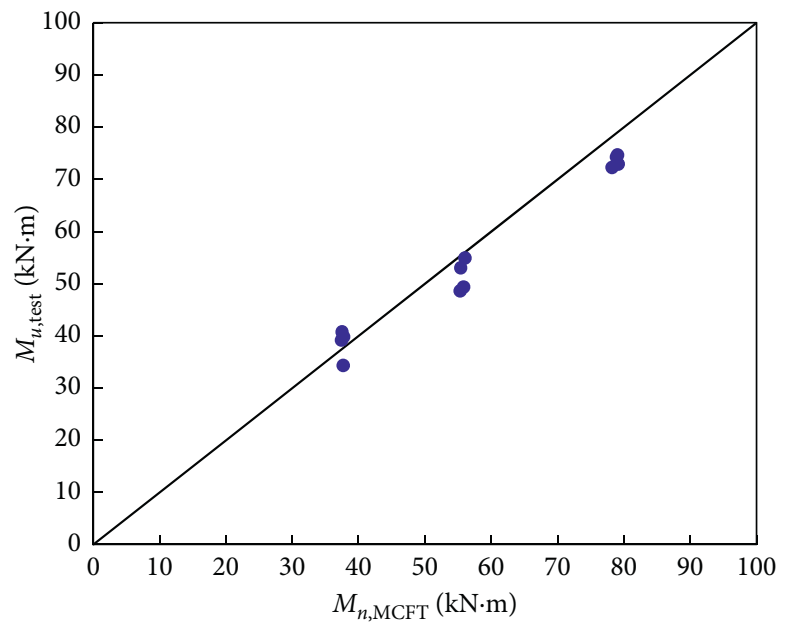

(c)

FIGURE 12: Comparison of flexural strength values. (a) ACI 318 provision. (b) EC 2 provision. (c) MCFT method. 


\section{Conclusions}

This paper presents an experimental study on the flexural characteristics of concrete beams containing RCA contents up to $100 \%$. The following conclusions are drawn from the test results:

(1) The test results showed that the number of cracks in the RCA beams was higher than that in the control beams. Therefore, the cracking pattern indicated that the RCA beams generally had closer crack spacing than the NCA beams. The closer cracking spacing in the RCA beams might be due to the effect of high shrinkage in the RCA beams.

(2) The overall flexural strength was affected by the RCA content. For beams with low rebar ratios of $0.50 \%$ and $0.79 \%$, the flexural strength values of the RCA beams significantly decreased as the RCA content increased. In contrast, for beams with a high rebar ratio of $1.14 \%$, the effect of the RCA contents on the flexural strength of the RCA beams was not significant.

(3) The ductility index was not significantly affected by the RCA content. The ductility of the RCA beams decreased slightly as the RCA content increased. Meanwhile, the ductility of the RCA beams decreased significantly as the rebar ratio increased.

(4) A comparison of the experimental flexural results with the calculated flexural results from the ACI 318 and EC 2 provisions indicated that the calculations underestimated the experimental results. This means that the prediction of flexural strength of the RCA members using the current provisions was conservative.

\section{Data Availability}

The data used to support the findings of this study are available from the corresponding author upon request.

\section{Conflicts of Interest}

The authors declare that they have no conflicts of interest.

\section{Acknowledgments}

This research was supported by the Korea Environment Industry and Technology Institute (KEITI) through the Public Technology Program based on the Environmental Policy Project, which was funded by the Korean Ministry of Environment (MOE) (2016000700002).

\section{References}

[1] S. Frondistou-Yannas, "Waste concrete as aggregate for new concrete," ACI Journal Proceedings, vol. 74, no. 8, pp. 373376, 1977.

[2] M. Etxeberria, A. R. Marí, and E. Vázquez, "Recycled aggregate concrete as structural material," Materials and Structures, vol. 40, no. 5, pp. 529-541, 2007.
[3] A. D. Buck, "Recycled concrete as a source of aggregate," ACI Journal Proceedings, vol. 74, no. 5, pp. 212-219, 1977.

[4] V. Corinaldesi, "Mechanical and elastic behaviour of concretes made of recycled-concrete coarse aggregates," Construction and Building Materials, vol. 24, no. 9, pp. 1616-1620, 2010.

[5] A. Ajdukiewicz and A. Kliszczewicz, "Influence of recycled aggregates on mechanical properties of HS/HPC," Cement and Concrete Composites, vol. 24, no. 2, pp. 269-279, 2002.

[6] W. H. Bai and B. X. Sun, "Experimental study on flexural behavior of recycled coarse aggregate concrete beam," Applied Mechanics and Materials, vol. 29-32, pp. 543-548, August 2010.

[7] K. Eguchi, K. Teranishi, A. Nakagome, H. Kishimoto, K. Shinozaki, and M. Narikawa, "Application of recycled coarse aggregate by mixture to concrete construction," Construction and Building Materials, vol. 21, no. 7, pp. 1542-1551, 2007.

[8] S. Huda and M. S. Alam, "Mechanical behavior of three generations of $100 \%$ repeated recycled coarse aggregate concrete," Construction and Building Materials, vol. 65, pp. 574-582, 2014.

[9] S.-C. Kou, C.-S. Poon, and H.-W. Wan, "Properties of concrete prepared with low-grade recycled aggregates," Construction and Building Materials, vol. 36, pp. 881-889, 2012.

[10] S. W. Tabsh and A. S. Abdelfatah, "Influence of recycled concrete aggregates on strength properties of concrete," Construction and Building Materials, vol. 23, no. 2, pp. 1163-1167, 2009.

[11] N. Deshpande, S. Kulkarni, and N. Patil, "Effectiveness of using coarse recycled concrete aggregate in concrete," International Journal of Earth Science and Engineering, vol. 4, pp. 913-919, 2011.

[12] A. Domingo-Cabo, C. Lázaro, F. López-Gayarre, M. A. Serrano-López, P. Serna, and J. O. Castaño-Tabares, "Creep and shrinkage of recycled aggregate concrete," Construction and Building Materials, vol. 23, no. 7, pp. 2545-2553, 2009.

[13] L. Butler, J. S. West, and S. L. Tighe, "The effect of recycled concrete aggregate properties on the bond strength between RCA concrete and steel reinforcement," Cement and Concrete Research, vol. 41, no. 10, pp. 1037-1049, 2011.

[14] M. Kikuchi, T. Mukai, and H. Koizumi, "Properties of concrete products containing recycled aggregate," in Proceedings of 2nd International Symposium on Demolition and Reuse of Concrete and Masonry, vol. 2, pp. 595-604, Tokyo, Japan, November 1988.

[15] S. Seara-Paz, B. González-Fonteboa, F. Martínez-Abella, and J. Eiras-López, "Flexural performance of reinforced concrete beams made with recycled concrete coarse aggregate," Engineering Structures, vol. 156, pp. 32-45, 2018.

[16] S. Sunayana and S. V. Barai, "Flexural performance and tension-stiffening evaluation of reinforced concrete beam incorporating recycled aggregate and fly ash," Construction and Building Materials, vol. 174, pp. 210-223, 2018.

[17] M. F. M. Fahmy and L. K. Idriss, "Flexural behavior of large scale semi-precast reinforced concrete T-beams made of natural and recycled aggregate concrete," Engineering Structures, vol. 198, Article ID 109525, 2019.

[18] T. Kang, W. Kim, Y.-K. Kwak, and S.-G. Hong, "Flexural testing of reinforced concrete beams with recycled concrete aggregates," ACI Structural Journal, vol. 111, no. 3, 2014.

[19] M. Arezoumandi, A. Smith, J. S. Volz, and K. H. Khayat, "An experimental study on flexural strength of reinforced concrete 
beams with $100 \%$ recycled concrete aggregate," Engineering Structures, vol. 88, pp. 154-162, 2015.

[20] H. R. Chaboki, M. Ghalehnovi, A. Karimipour, and J. de Brito, "Experimental study on the flexural behaviour and ductility ratio of steel fibres coarse recycled aggregate concrete beams," Construction and Building Materials, vol. 186, pp. 400-422, 2018.

[21] J. D. Brito, J. Ferreira, J. Pacheco, D. Soares, and M. Guerreiro, "Structural, material, mechanical and durability properties and behaviour of recycled aggregates concrete," Journal of Building Engineering, vol. 6, pp. 1-16, 2016.

[22] M. S. Meddah, S. Zitouni, and S. Belâabes, "Effect of content and particle size distribution of coarse aggregate on the compressive strength of concrete," Construction and Building Materials, vol. 24, no. 4, pp. 505-512, 2010.

[23] American Society for Testing and Materials (ASTM), Standard Test Method for Compressive Strength of Cylindrical Concrete Specimens, ASTM C39, West Conshohocken, PA, USA, 2020.

[24] Korea Industrial Standard, Standard Test Method for Compressive Strength of Concrete; KS F 2405, Korea Industrial Standards, Seoul, South Korea, 2010.

[25] Korea Concrete Institute, Korea Design Code for Structural Concrete, Korea Concrete Institute, Seoul, South Korea, 2012.

[26] S. H. Ahmad and R. Barker, "Flexural behavior of reinforced high-strength lightweight concrete beams," ACI Structural Journal, vol. 88, no. 1, 1991.

[27] ACI Committee 318, "Building code requirements for structural concrete (ACI 318-14): an ACI standard: commentary on building code requirements for structural concrete (ACI 318R-14), an ACI Report," 2014.

[28] European Committee for Standardisation, EN 1992-1-1: Eurocode 2: Design of Concrete Structures-Part 1-1: General Rules and Rules for Buildings, European Committee for Standardisation, Brussels, Belgium, 2004.

[29] E. Bentz, Sectional Analysis of Reinforced Concrete Members, University of Toronto, Toronto, Canada, 2000.

[30] Response 2000 Program, http://www.ecf.utoronto.ca/ bentz/ r2k.htm.

[31] A. B. Sturm, P. Visintin, and D. J. Oehlers, "Time-dependent serviceability behavior of reinforced concrete beams: partial interaction tension stiffening mechanics," Structural Concrete, vol. 19, no. 2, pp. 508-523, 2018.

[32] H. Dong, Y. Song, W. Cao, W. Sun, and J. Zhang, "Flexural bond behavior of reinforced recycled aggregate concrete," Construction and Building Materials, vol. 213, pp. 514-527, 2019. 